\title{
Technological and Economic Optimization of Functional Ready to Eat Meal
}

\author{
Amalia Conte ${ }^{1,2}$, Antonio Stasi ${ }^{3}$, Vittoria Pilone ${ }^{3}$, Daniela Gammariello ${ }^{1}$, Lucia Padalino ${ }^{1}$, Francesco Bimbo ${ }^{3}$, \\ Antonio Lopolito ${ }^{3} \&$ Matteo Alessandro Del Nobile ${ }^{1,2}$ \\ ${ }^{1}$ Istituto per la Ricerca e le Applicazioni Biotecnologiche per la Sicurezza e la Valorizzazione dei Prodotti Tipici \\ e di Qualità, Università degli Studi di Foggia, Via Gramsci, Foggia, Italia \\ ${ }^{2}$ Università di Foggia, Dipartimento di Scienze degli Alimenti (DISA), Via Napoli, Foggia, Italia \\ ${ }^{3}$ Università di Foggia, Dipartimento di Scienze delle Produzioni e dell'Innovazione nei Sistemi Agro-alimentari \\ Mediterranei (PRIME), Via Napoli, Foggia, Italia \\ Correspondence: Matteo Alessandro Del Nobile, Istituto per la Ricerca e le Applicazioni Biotecnologiche per la \\ Sicurezza e la Valorizzazione dei Prodotti Tipici e di Qualità, Università degli Studi di Foggia, Via Gramsci, \\ Foggia 89/91-71122, Italia. Tel: 39-881-589-242. E-mail: ma.delnobile@unifg.it
}

Received: January 11, 2012 Accepted: February 2, 2012 Online Published: July 17, 2012

doi:10.5539/jfr.v1n3p192 URL: http://dx.doi.org/10.5539/jfr.v1n3p192

\begin{abstract}
A ready meal based on precooked gluten-free pasta with a yogurt-based sauce enriched with probiotic bacteria was developed and optimized from both the nutritional and sensory point of view. Conceptually, the work aims at understanding the innovation stress in consumers and check whether the "perfect beauty" of a complex food product innovation, which is extremely admirable from a food technology point of view, could be effectively appreciated by consumers. In other words, we are interested in knowing whether there exists a gap between science-based or "innovation-leading" technologists' food preferences and consumers' preferences, which are taste, information, price and promotion driven.
\end{abstract}

\section{Practical Applications}

The increasing basic awareness of the metabolic and physiological action of functional compounds, that bring better health benefits than conventional products when added to foods, is the driving force of this sector. Many companies have invested in development, production and marketing of nutraceuticals since they recognize the opportunity and urgency of aiming towards strengthening the tendency for innovation as a vehicle for the completion and/or consolidation of the process of internationalization. The current work could contribute the give answer to the need to develop processes focused on optimisation of nutrition and improvement of eating habits.

Keywords: functional food, prebiotic, probiotic, food processing, consumer attitudes

\section{Introduction}

Typically, a functional food contains ingredients with a specific health benefit (Niva, 2007), such as vitamins and/or minerals as vitamin C, vitamin E, folic acid, zinc, iron, and calcium (Sloan, 2000). Subsequently, the focus shifted to foods fortified with various micronutrients, such as omega-3 fatty acid, phytosterol, and soluble fibre to promote good health or to prevent diseases such as cancers (Sloan, 2002). More recently, food companies have taken further steps to develop food products that offer multiple health benefits in a single food (Sloan, 2004). Functional foods have been developed in virtually all food categories. Recently, the market of functional food is dominated by gut health products, in particular probiotics and prebiotics (Alzamora, Salvatori, Tapia, López-Malo, Welti-Chanes \& Fito, 2005; Jones \& Jew, 2007; Saarela, Lähteenmäki, Crittenden, Salminen, \& Mattila-Sandholm, 2002). Probiotics are defined as "live microorganisms, as they are consumed in adequate numbers to confer a health benefit on the host", with ongoing controversy as to whether cultures must be viable for efficacy in all cases (Charalampopoulos, Pandiella, \& Webb, 2003; Charalampopoulos, Wang, Pandiella \& Webb, 2002; Stanton, Ross, Fitzgerald, \& Van Sinderen, 2005). Lactic acid bacteria (LAB) and bifidobacteria, the most studied and widely employed bacteria within the probiotic field, are normal components of the intestinal microbiota and have a long tradition of safe application within the food industry (Kociubinski \& 
Salminen, 2006). Prebiotics are non-digestible food ingredients that beneficially affect the host by stimulating growth and/or activity of one or limited number of bacteria in the colon, thus improving host health (Charalampopoulos et al., 2003; Stanton et al., 2005). Among them, fructo-oligosaccharide (FOS), inulin, isomalto-oligosaccharides (IMO), polydextrose, lactulose and resistant starch are considered as the main prebiotic components. Inulin and oligofructose, non-digestible fermentable fructans, are abundantly studied as established prebiotics (Gibson, 2004). Given the commercial success and growth of yogurt as a healthy choice among consumers, it is considered a good vehicle for probiotics (Brannon, 2006). Probiotic yogurt containing Lactobacillus acidophilus, Bifidobacterium spp. and Lactobacillus casei can be considered a functional product (Shah, 2007).

Besides dairy products, another important class of functional foods encompasses cereal (grain) products. Grains, such as wheat, maize, rice and oats are examples of functional cereal products that have been modified to provide health benefits over and above basic nutrition.

Understanding consumer selection of functional products, hence, consumers' perception towards these foods is of crucial importance (Gilbert, 1997; Grunert, Bech-Larsen, \& Bredahl, 2000; Weststrate, Van Poppel, \& Verschuren, 2002). Food advances in terms of convenience, taste and functionality has allowed a substantial increase of both food value and price (Reilly, 1982; Glanz, Basil, Maibach, Goldberg, \& Snyder, 1998; Verlegh \& Candel, 1999). Educational attainments, as well as cultural aspects of new generations, compared to a few decades ago, enabled consumers to understand food innovations and use them for their convenience (Nayga, 1996). Nowadays, consumers demand for fresh, healthy, safe and good quality foods. Thus, complex preferences allow developing niche markets for complex products that satisfy specific consumers' needs. On the other hand, the development of highly specific products could be risky in terms of effective communication and market placement in order to have successful products in terms of consumers' appreciation - volumes purchased - and monetary spending. Nonetheless, most of the food technology, microbiology and other subject that contribute to the intrinsic innovation of foods might have the prejudice of consumers' preferences increasing as healthiness, safety and convenience increase. On the other hand, communicating an innovation, especially in food market, is a difficult task and most of the time the innovation gap with products already on the shelves is a relevant factor in determining innovative products acceptability.

At this purpose, we developed a novel food recipe that would allow capturing the whole set of consumers most preferred attributes for which a vast literature has shown positive willingness to pay (hereafter WTP) and strong market potential (Gilbert, 1997; Grunert et al., 2000; Weststrate et al., 2002). Due to the diffusion of pasta throughout the world and the popularity of both traditional and non-conventional cereal grains, a tangible impulse to the development of ready to eat functional foods based on pasta has been widely provided.

At this regard, our general objective is to find whether such a complex product could be successful on market. In order to satisfy this objectives, the following phases need to be overcome: a) developing a multifunctional ready to eat food product, which is the food technology objective; b) optimizing the recipe with the help of expert panelists; c) running a market segmentation; d) analyzing consumers' preferences through a conjoint analysis; e) determining the WTP of such a product and the contribution of each attribute to WTP; f) developing a logistic function linking innovation intensity and market success probability.

\section{Materials and Methods}

\subsection{Maize-based Pasta Preparation}

The maize flour was bought from Bongiovanni mill (Mondovì, Cuneo, Italy) while inulin was purchased at the company Beneo Orafit (Belgium). To prepare non-conventional dough, a portion of maize flour was pre-gelatinized. In a steam cooker (LT50 2E Namad, Rome, Italy) water, flour and 15\% (w/w) inulin were mixed and heated to $80^{\circ} \mathrm{C}$. Subsequently, in order to prepare non-conventional pasta the pre-gelatinized maize flour was cooled to $40^{\circ} \mathrm{C}$ and then monoglycerides $(1 \% \mathrm{w} / \mathrm{w})$ were added to the mixture of the remaining maize flour. Dough based on the sole maize flour $(100 \%)$ was also prepared and then used as the control (CTRL). Macaroni samples were produced by a pilot plant made of an extruder (60VR, Namad, Rome, Italy) and a dryer (SG600, Namad). During drying process, the following conditions were applied: $1^{\circ}$ step of $20 \mathrm{~min}$ at $55^{\circ} \mathrm{C} ; 2^{\circ}$ step of 580 min at $75^{\circ} \mathrm{C} ; 3^{\circ}$ step of $40 \mathrm{~min}$ at $60^{\circ} \mathrm{C} ; 4^{\circ}$ step of $20 \mathrm{~min}$ at $45^{\circ} \mathrm{C}$ and $5^{\circ}$ step of $840 \mathrm{~min}$ at $40^{\circ} \mathrm{C}$.

\subsection{Pre-cooking and Cooking Process of Pasta}

One litre of water was brought to boil. After that, $100 \mathrm{~g}$ of pasta were added and cooked for $10 \mathrm{~min}$ for the sample CTRL whereas $7 \mathrm{~min}$ for the sample with $15 \%$ inulin. Half a minute before the end of pre-cooking time a thread of oil was added to prevent the probability of the pasta clumping during storage. Cold water was added to 
further stop the cooking process of pasta that was then drained and stored in a refrigerator at $4{ }^{\circ} \mathrm{C}$. $24 \mathrm{~h}$ after pasta was heated in a microwave oven (Whirlpool Europe srl, model 542-562) operating at $650 \mathrm{~W}$ continuous power for $1 \mathrm{~min}$.

\subsection{Probiotic Yogurt-based Sauce Preparation}

One litre skimmed UHT milk was treated in autoclave at $90^{\circ} \mathrm{C}$ for 5 minutes and then cooled to about $40^{\circ} \mathrm{C}$. The heat treatment was aimed to improve the development of microbial flora subsequently inoculated, making the clot more compact and reduce the phenomenon of serum separation. The inoculum consisted of a mixture of Lactobacillus bulgaricus and Streptococcus thermophilus (D Jointech, Centro Sperimentale del Latte, Italy) and of potentially probiotic microorganisms Bifidobacterium lactis LY0018 (Probiotical, Italy) added. The inoculum in the rate of $0.15 \%$ was added to milk; inoculated milk was mixed, portioned into the jars and incubated in a yogurt maker (Girmi, Italy) ranging from 3 to 6 hours depending on the nature of the inoculum and temperature. After incubation, the yogurt was cooled immediately to stop bacterial growth and stored at $4{ }^{\circ} \mathrm{C}$. A probiotic yogurt was obtained and 9 types of sauces were formulated as reported in the Table 1.

Table 1. Description of ingredients utilized in formulation' sauces

\begin{tabular}{cl}
\hline Sauces & \multicolumn{1}{c}{ Ingredients } \\
\hline 1 & pesto (basil leaves, pine nuts, garlic, Parmigiano cheese and olive oil) \\
2 & capper, blacks olive, anchovy-paste \\
3 & extra-virgin olive oil, garlic, chive, soy sauce, salt \\
4 & smoked salmon \\
5 & cream, chive, salt, pepper, nutmeg \\
6 & peas, carrots, oil, salt, pepper \\
7 & ripe tomatoes, Parmigiano cheese, basil, red pepper, extra virgin olive oil \\
8 & walnut, marjoram, Parmigiano cheese, salt, pepper \\
9 & ricotta cheese, capers, pickles, anchovy-pasta \\
\hline
\end{tabular}

\subsection{Sensory Analysis}

Pre-cooked and cooked pasta samples were submitted to a panel of ten trained tasters in order to evaluate main sensory attributes. The panellists were selected on the basis of their sensory skills (ability to accurately determine and communicate the sensory attributes, appearance, odour, flavour and texture of a product) and trained in four sessions held over two days (2 sessions/day, 2 h/session) (Meilgaard, Civille, \& Carr, 1999). They were trained in sensory vocabulary and in the identification of particular attributes, prior to testing macaroni, by evaluating commercial conventional and non-conventional pasta. The panellists were asked to indicate colour, homogeneity, resistance to break and overall quality of pre-cooked pasta. Firmness, bulkiness, adhesiveness, colour, odour, taste and overall quality of cooked pasta were also judged. To this aim, a nine-point scale, where 1 corresponded to extremely unpleasant, 9 to extremely pleasant and 5 to satisfactory, was used to quantify each attribute (Chillo, Laverse, Falcone, \& Del Nobile, 2007; Petitot, Boyer, Minier, \& Micard, 2010). Data on sensory analysis were compared by a one-way variance analysis (ANOVA). A Duncan's multiple range test, with the option of homogeneous groups $(\mathrm{p}<0.05)$, was carried out to determine significant differences between pasta samples. STATISTICA 7.1 for Windows (StatSoft, Inc, Tulsa, OK, USA) was used for this purpose.

The sensory study on sauces was performed by using two different experimental procedures: a panel test to choice the most pleasant formulation and a consumer test to evaluate the acceptability of sauces. The first test was conducted by a trained panel of 7 assessors. A 5-point scale (Dello Staffolo, Bertola, Martino, \& Bevilacqua, 2004) ranging from "like very much" to "dislike" was used to determine the degree of acceptance of sauces. The responses were converted to numerical values ranging from 1 for dislike to 5 for like very much. An additional consumer test was conducted with 50 tasters consisting of 16 employees and 34 students from the University of Foggia. The assessors were presented with $30 \mathrm{~mL}$ of the above selected sauces at room temperature $\left(25^{\circ} \mathrm{C}\right)$. Water was given to the assessors for palate cleansing between samples. According to Iwe (2002), a 9-point scale, where 9 corresponded to like extremely and 1 to dislike extremely, was used. Odor, flavor, appearance, acidity, sweet, texture and overall quality were evaluated as sauces attributes. 


\subsection{Consumers' data collection}

After the separate evaluation of gluten-free pasta and yogurt sauces, the two ingredients were combined to formulate a ready-to-eat multifunctional meal. The three most prized yogurt sauces previously selected were used for this step.

Data collection for commercial viability measurements has been carried out by means of a survey. Interviews have been conducted on a random sample of consumers, before their meal at the entrance of a cafeteria/snack bar which hosts a wide range of consumers, high school students, and housewives, employees of the local government, and workers with various levels of education. Having selected interviewees randomly at the entrance of those places we have selected a sample with the characteristics of the participants of this market in the city of Foggia, we consider this as the segment of people that might be interested to the innovative products we proposed. However, any inference made on the base of this sample, then, can only be referred to the city the interviews were carried on.

From the sample descriptive (Table 2) we noticed market participants with the following characteristics: younger than Italian average, have higher income and high education, practice sport for two hours a day, $30 \%$ of them has health issues for which they need to take medications, they pay high attention to food quality and often read the label, their behavior is experimental and $50 \%$ of the segment consumes already functional foods.

Table 2. Descriptive statistics of ready to eat meals market segment

\begin{tabular}{lcccc}
\hline Variable & Mean & Standard Deviation & Minimum & Maximum \\
\hline Age & 35.500 & 12.902 & 19 & 57 \\
Children & 1.000 & 1.902 & 0 & 12 \\
Education & 3.625 & 0.841 & 3 & 5 \\
Full time & 2.917 & 2.181 & 0 & 7 \\
Income & 2.771 & 0.973 & 1 & 5 \\
Sport & 2.479 & 3.229 & 0 & 5 \\
Health issues & 0.292 & 0.459 & 0 & 1 \\
Eating as physiological need & 0.375 & 0.489 & 0 & 1 \\
Eating to stay in companionship & 0.188 & 0.394 & 0 & 1 \\
Eating for pleasure & 0.188 & 0.394 & 0 & 1 \\
Food intolerance & 0.106 & 0.312 & 0 & 1 \\
Attention to food quality & 3.029 & 1.299 & 0 & 5 \\
Reading labels & 2.827 & 1.681 & 0 & 5 \\
Eating functional foods & 0.479 & 0.505 & 0 & 1 \\
Like to experiment new meals & 0.938 & 0.245 & 0 & 1 \\
Expenditure per portion & 0.771 & 1.259 & 0 & 4 \\
\hline
\end{tabular}

\subsection{The Economic Theory of Choices}

While production and sensory analysis do not need any behavioral assumption, economic behavior study has to be grounded on rational response of consumers to external stimuli. Therefore, in order to proceed with the full optimization and pricing analysis we must discuss the reference economic theory that encompasses the optimization of consumers' preferences given their budget constraint and other socio-demographic characteristics. Referring to this theory allows having rules enabling market segmentation (obj. c), analyzing consumers' preferences through a conjoint analysis (obj. d) and determining the WTP (obj. e).

Market segmentation and consumers' preferences measurements refer more technically to "conjoint choice experiments". Those types of procedures have become very popular, being a particularly attractive approach, and being a valid alternative to other methods such as contingent valuation (Burton, Rigby \& Young, 2001). The 
basic assumption of the Choice Modeling (hereafter $\mathrm{CM}$ ) is that products have to be defined on a limited number of key attributes, each with a limited number of levels. Based on these attributes and levels a set of products are constructed and consumers have to choose their most preferred option from a small set of profiles. Attributes usually refer to characteristics known to consumers, such as extrinsic attributes. However, the attractiveness of this set of methods consists in identifying choices that represent the trade-offs that are made in actual decisions.

Random Utility Theory affirms that individuals choose the alternative yielding the greater net utility, which could be represented as follows:

$$
U_{i j}=V_{i j}+\varepsilon_{i j}=X_{i j} \beta+\varepsilon_{i j}
$$

Where $i=1, \ldots, N$ indicates the individuals, and $j=1, \ldots, J$ indicates the alternatives.

Equation (1) shows that the utility $U$ of the individual $i$ relative to the product $j$, is composed of the indirect utility $V$, which is known to researchers, and the stochastic term $\varepsilon$, which is unknown to researcher but known by the individual. The indirect utility includes a matrix of product attributes $X$, measure as discrete, dummy and continuous variables, and a vector of coefficients $\beta$.

\subsection{Empirical Economic Analysis}

McFadden (1974) has shown that a random utility model can be estimated through the maximization of the logarithmic version of a conditional logit likelihood function:

$$
\operatorname{Prob}\left(Y_{i}=j\right)=\exp \left[\lambda_{j} \boldsymbol{X}_{j}^{\prime} \beta\right] / \Sigma_{j} \exp \left[\lambda_{j} \boldsymbol{X}_{j}^{\prime} \beta\right]
$$

Where $Y$ denotes the choice made ( 0 when an option is not chosen; 1 otherwise). The model estimates sign and intensity of effects through the $\beta$ parameters. Additionally, the model accounts for preferences scale because of the parameters $\lambda_{j}$, which accounts for preferences heteroscedasticity over the options proposed to consumers.

Conditional Logit, Mixed Logit and Heteroscedastic Extreme Value (HEV) has been widely used in the empirical analysis regarding genetically modified food (Burton et al., 2001; Roselli, Seccia, \& Stasi, 2006; Stasi, Carlucci, \& Seccia, 2008), environmental goods evaluation (Morrison, Blamey, Bennet, \& Louviere, 1996; Adamowicz, Boxall, Williams, \& Louviere, 1998; Blamey, Bennet, Morrison, Louviere, \& Rolfe, 2001; Bennet 1999; Hansen \& Smidth 1999), food labeling and food quality (Cicia, Del Giudice, \& Esposito, 2004; Cicia, Del Giudice, \& Scarpa, 2002; Bjorner, Hansen, \& Russel, 2004).

Parameters can be combined in order to assign a monetary value to consumers' preferences. This WTP could be intended as the change in price that, after a change in product quality, brings back the utility to its initial level (Roselli et al., 2006; Cicia et al., 2002; Burton et al., 2001). This rationale refers to the part-worth evaluation:

$$
\begin{gathered}
\beta_{1} \times(\text { High Quality dummy }=1)+\beta_{2} \times \text { Price }=\beta_{2} \times(\text { Price }+ \text { WTP })+\varepsilon_{0} \\
E(W T P)=\beta_{1} / \beta_{2}, \quad \text { when } E\left(\varepsilon_{0}\right)=0
\end{gathered}
$$

The condition $\varepsilon_{0}$ equals to zero affirms the condition of mean preferences. In reality, consumers show heterogeneous preferences so each individual WTP may deviate from this estimation, although our estimation refers to a general value of the sample.

The aim of the economic analysis is to measure consumers' preferences for the multifunctional ready to eat pasta through a simulated market. Those measures allow, first of all, identifying the innovation that will have sure success on the market. Last but not least, the measurement of the willingness to pay in terms of price difference between a non functional alternative (or non gluten free alternative, or non ready to eat alternative) provides a measurement of the differentiation level between the functional and the conventional version, which is already on the market. This measure allows predicting the profit potentiality of the innovation.

\subsection{Survey Preparation and Segment Selection}

A three parts questionnaire has been prepared. The first part included the selection of the most preferred recipe among the three selected by the panel of experts. The second part includes question for the collection of socio-demographic information. The third concerns the investigation on consumers' preferences towards different type of products, differentiated by levels of labeled information.

Given the attributes of the invented product, based on technological possibilities and innovations, we have the following set: functional bacteria, maize based pasta, which is gluten-free, and ready to eat possibility. At this regard, having the objective of presenting the complete product, which includes the label and its information, we developed a set of attributes level that could be actually chosen for producing a novel food. Therefore, beside the presence or absence of a certain attribute in a product, we decide to hypothesize different levels. 
Attributes and their levels are shown in Table 3. If all the possible combinations/alternatives, which are 27, were presented to consumers, altogether or a random selection of them, confusion and tiredness would have occurred, leading to a biased analysis (Train, 2009). In order to reduce the number of alternatives presented to interviewees, a Latin Square experimental design that reduces the alternatives with orthogonality criteria (uncorrelated alternatives) has been applied, giving rise to 15 alternatives, representing most of the variability of the 27 . In this way, direct interview, with no tiredness bias, are possible.

Table 3. Attributes and their levels

\begin{tabular}{ll}
\hline Attributes & Levels \\
\hline Price & $-15 \% ;-10 \% ; 0 \% ; 10 \% ; 15 \% ; 20 \% ; 30 \% ; 40 \%$ \\
Functional Information & $-(0)$ \\
& Functional Claim (1) \\
& Health Claim (2) \\
& $-(0)$ \\
Gluten free & Gluten Free (1) \\
& Gluten free from Maize (1) \\
& Normal, 20 min preparation $(0)$ \\
Cooking rapidity & Medium rapidity, precooked, 10 min preparation (1) \\
& Rapid, to warm up, 3 min preparation (2) \\
\hline
\end{tabular}

Having the set of alternatives, choice sets (groups of three alternatives formed by base product; alternative 1; alternative 2) from which consumers are asked to choose, have been formed by means of random draws without repetition from the 15 alternatives. Finally, price variations have been assigned randomly to alternatives, assuring that no dominance was created within a choice-set (Table 4). Prices of the other alternatives, then, were calculated applying the percentage variation hypothesized. 30 choice sets were created and assigned to tree different questionnaires (Burton et al., 2001). Data are collected through a questionnaire-based survey.

Table 4. Example of choice set proposed to consumers

\begin{tabular}{|c|c|c|c|c|c|}
\hline \multicolumn{6}{|c|}{ Pick one among those alternative products } \\
\hline$€$ & 3.00 & $€$ & 3.74 & $€$ & 4.72 \\
\hline & & \multicolumn{2}{|c|}{$\begin{array}{l}\text { Improves immune system and } \\
\text { mineral absorption capacity }\end{array}$} & \multicolumn{2}{|c|}{$\begin{array}{l}\text { Improves immune system and } \\
\text { mineral absorption capacity }\end{array}$} \\
\hline & & & & \multicolumn{2}{|c|}{ Gluten Free } \\
\hline \multicolumn{2}{|c|}{20 min. preparation } & \multicolumn{2}{|c|}{10 min. preparation } & \multicolumn{2}{|c|}{3 min. preparaion } \\
\hline
\end{tabular}

\section{Results and Discussion}

\subsection{Sensory Analysis of Prebiotic Pasta}

Sensory properties of all pasta samples are listed in Tables 5 and 6 . As can be seen, among pre-cooked macaroni, the sample enriched with $15 \%$ inulin recorded a high score of overall quality and did not show significant differences respect to the CTRL. The sole difference due to the presence of inulin is a certain lack of resistance in the functional macaroni, compared to pasta without any enrichment. Regarding the cooked pasta, sample with inulin also recorded a positive score of overall quality that did not differ significantly from the CTRL, even though the presence of inulin slightly affected pasta firmness. This attribute in pasta can be generally related to hydration of starch granules during cooking process and due to the subsequent embedding of gelatinizing starch granules in the matrix. Therefore, the decrease in firmness may be associated to a reduction in starch gelatinization (Brennan, Kuri, \& Tudorica, 2004). Dietary fibres that are highly water-binding macromolecules 
generally compete with starch for water absorption and hence, limit starch swelling and gelatinization, resulting in a higher endothermic peak temperature value (Collar, Santos, \& Rosell, 2006). High transition temperatures have also been reported to result from a high degree of starch crystallinity, which provides structural stability and makes the granule more resistant toward gelatinization (Singh, Singh, Kaur, Sodhi, \& Gill, 2003). The reduction of starch swelling of samples containing inulin would result from the inulin preferentially hydrating, aggregating, and forming a matrix, encasing starch granules in a semisolid gel (Tolstoguzov, 2003). This encasing of starch granules would possibly limit water movement to the starch granules in the pasta, reducing gelatinization events.

Table 5. Results of sensory evaluation of precooked gluten-free pasta

\begin{tabular}{cccccccccccc}
\hline & & & & \multicolumn{5}{c}{ Pre-cooked pasta } \\
& Elasticity & Firmness & Fibrous & Bulkiness & Adhesiveness & Color & Homogeneity & Odor & Taste & $\begin{array}{c}\text { Global } \\
\text { Quality }\end{array}$ \\
\hline Pasta CTRL & $7.2^{\mathrm{a}} \pm 0.18$ & $7.6^{\mathrm{a}} \pm 0.40$ & $8.0^{\mathrm{a}} \pm 0.18$ & $7.5^{\mathrm{a}} \pm 0.40$ & $8.0^{\mathrm{a}} \pm 0.18$ & $7.5^{\mathrm{a}} \pm 0.40$ & $8.0^{\mathrm{a}} \pm 0.18$ & $7.6^{\mathrm{a}} \pm 0.40$ & $7.4^{\mathrm{a}} \pm 0.40$ & $7.5^{\mathrm{a}} \pm 0.28$ \\
Pasta/Inulin & $7.1^{\mathrm{a}} \pm 0.28$ & $7.5^{\mathrm{a}} \pm 0.34$ & $8.0^{\mathrm{a}} \pm 0.18$ & $7.8^{\mathrm{a}} \pm 0.34$ & $7.8^{\mathrm{a}} \pm 0.18$ & $7.5^{\mathrm{a}} \pm 0.40$ & $8.0^{\mathrm{a}} \pm 0.18$ & $7.6^{\mathrm{a}} \pm 0.38$ & $7.6^{\mathrm{a}} \pm 0.38$ & $7.4^{\mathrm{a}} \pm 0.38$ \\
\hline
\end{tabular}

Table 6. Results of sensory evaluation of cooked gluten-free pasta

\begin{tabular}{lcccccccccc}
\hline & & \multicolumn{9}{c}{ Cooked pasta } \\
& Firmness & Fibrous & Bulkiness & Adhesiveness & Color & Homogeneity & Odor & Taste & $\begin{array}{c}\text { Global } \\
\text { Quality }\end{array}$ \\
\hline Pasta CTRL & $7.7^{\mathrm{a}} \pm 0.40$ & $8.0^{\mathrm{a}} \pm 0.18$ & $7.5^{\mathrm{a}} \pm 0.40$ & $8.0^{\mathrm{a}} \pm 0.18$ & $7.5^{\mathrm{a}} \pm 0.40$ & $8.0^{\mathrm{a}} \pm 0.18$ & $7.7^{\mathrm{a}} \pm 0.40$ & $7.7^{\mathrm{a}} \pm 0.40$ & $7.6^{\mathrm{a}} \pm 0.28$ \\
Pasta /Inulin & $7.6^{\mathrm{a}} \pm 0.34$ & $8.0^{\mathrm{a}} \pm 0.18$ & $7.8^{\mathrm{a}} \pm 0.34$ & $8.0^{\mathrm{a}} \pm 0.18$ & $7.5^{\mathrm{a}} \pm 0.40$ & $8.0^{\mathrm{a}} \pm 0.18$ & $7.6^{\mathrm{a}} \pm 0.38$ & $7.6^{\mathrm{a}} \pm 0.38$ & $7.5^{\mathrm{a}} \pm 0.38$ \\
\hline
\end{tabular}

\subsection{Sensory Analysis of Probiotic Yogurt-based Sauce}

A 5-point scale was used to determine the most prized sauces. The results indicated that only the sauce number 4 was accepted with a score 5 (like very much) (Table 1); almost all assayed samples were rated as acceptable with a score 3 (neither like nor dislike), considered as the acceptable treshold (Dello Staffolo et al., 2004). The 1 and 9 sauces got above category 4 (like). Therefore, the number 1, 4 and 9 sauces were used for the subsequent test. A 9-point scale was used to determine the sauce preferred by the majority of consumers. Figure 1 shows the frequency of acceptance of each sauce over the total number of consumers (50).

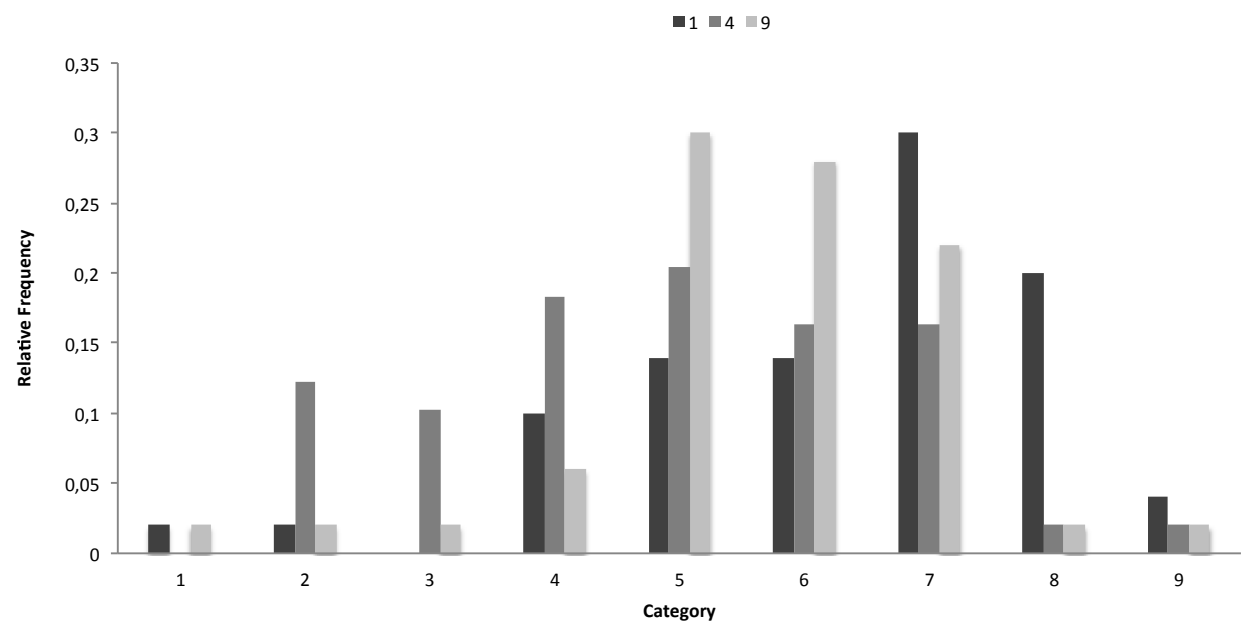

Figure 1. Results of consumer test on the three selected yogurt sauces

The tests showed that the assessors graded more frequently the three sauces with scores ranged from 5 to 7 , from "neither like nor dislike" (score 5) to "like moderately" (score 7). The results also indicated that only the pesto sauce was accepted with a score 8: "Like very much". Data of other sensory characteristics (odour, flavour, 
appearance, acidity and sweet) were not shown as almost all assayed yogurt sauces have scores above category 5 (neither like nor dislike), considered the acceptability threshold (Chillo et al., 2007).

\subsection{Consumers' Preferences: Empirical Results}

The models compared produced comparable results and more specifically the inferior model, the conditional logit (Model I), resulted the best compared to other specification, respectively the Hetheroskedastic Extreme Value Model "HEV" (Model II) and the Random Effect (Model III).

The Table 7 presents the results. For brevity, sign and significance are discussed in this section. Expectations from economic theory are here confirmed from the economic model. In fact, as price increases consumers' preferences decrease. Among the quality attributes, only functional and health characteristic generate a significant increase in consumers' preferences. By the way, the functional information attracts consumers more than health information. At this regard one might justify these results with trust level for the given labeled information. The other attributes, by contrast, show negative preferences. This is verified for both gluten free information levels and cooking time preparation. In the first case, results might be justified by consumers assuming gluten-free products to be less tasty. The second result, negative preferences for lower preparation time meals, could be justified by the fact that people in the shops we have conducted the interviews purchased ready to eat products and they do not have to prepare directly the meal they associated better taste to longer preparation meals.

Table 7. Results of the econometric models

\begin{tabular}{lcccccc}
\hline \multicolumn{1}{c}{ Variable } & \multicolumn{2}{c}{ Conditional Logit } & \multicolumn{2}{c}{ HEV } & \multicolumn{2}{c}{ Random Price } \\
& \multicolumn{2}{c}{ Model I } & \multicolumn{2}{c}{ Model II } & \multicolumn{2}{c}{ Model III } \\
& Parameter & P-Value & Parameter & P-Value & Parameter & P-Value \\
\hline Price & -0.475 & 0.044 & -0.511 & 0.058 & -0.475 & 0.110 \\
Random Price Effect & - & - & - & - & 0.006 & 0.900 \\
Functional Claim & 1.060 & 0.000 & 1.160 & 0.003 & 1.060 & 0.000 \\
Health Claim & 0.964 & 0.003 & 1.092 & 0.020 & 0.964 & 0.004 \\
Gluten-free & -0.501 & 0.061 & -0.546 & 0.080 & -0.501 & 0.100 \\
Gluten free from maize & -0.455 & 0.045 & -0.477 & 0.057 & -0.455 & 0.051 \\
10 min preparation & -0.702 & 0.002 & -0.747 & 0.007 & -0.702 & 0.003 \\
3 min preparation & -0.291 & 0.192 & -0.324 & 0.234 & -0.291 & 0.252 \\
Scale 2 & - & - & 0.909 & 0.000 & - & - \\
Scale 3 & - & - & 0.890 & 0.001 & - & - \\
Log Likelihood & -233.989 & -233.901 & & -233.989 \\
\hline
\end{tabular}

When analyzing consumers' preferences in terms of WTP (Table 8) we noticed that compared to a $3 €$ for a portion of meal without additional quality attributes, products with functional and health information could be paid well above the base price, in fact the WTP reaches and goes beyond the $5 €$. In the other cases, because of negative preferences, WTP goes below the base price.

At this point, it is necessary to analyze the phenomenon from a broader point of view. Results referred to a single quality attribute might not be, in fact, the best approach to analyze complex quality innovative food products. Therefore, the second advance we propose here is based on the consideration of consumers' preferences being related to the innovation level and to the understandability and trust towards the declared innovation. At this regard, health resolutions, for example, which are usually associated to medications, can be difficultly associated to food. This mechanism, therefore, may generate mistrust. Taste expectations are also relevant in this discussion; products where the innovation forms expectations about changing the original taste of the food, might generate aversion. 
Table 8 . Estimates of purchasing probability based on innovation intensity

\begin{tabular}{lccc}
\hline \multicolumn{1}{c}{ Parameter } & Estimate & $\mathrm{t}$ Value & $\mathrm{Pr}>|\mathrm{t}|$ \\
\hline Intercept & 1.394 & 2.554 & 0.110 \\
Price & 0.035 & 0.032 & 0.858 \\
Innovation intensity 1 & -2.389 & 4.707 & 0.030 \\
Innovation intensity 2 & 0.705 & 3.758 & 0.053 \\
Innovation intensity 3 & -0.064 & 3.342 & 0.068 \\
\hline
\end{tabular}

Considering the attributes into three different levels of innovation (Table 9), which adds up the single products innovative quality attributes we can estimate a logistic function purchasing probability. More specifically, we refer to "innovation intensity 1" for the base product plus one innovation (functional, gluten free, shorter preparation time), "innovation intensity 2 " for products presenting a combination of quality attributes, e.g. gluten free, functional, shorter preparation time; "innovation intensity 3" for products presenting one or a combination of more quality attributes of the upper innovation level such as health resolution, gluten free with maize flour, or 3 minutes preparation time.

Table 9. Willingness to pay

\begin{tabular}{lcc}
\hline Attribute & WTP (final price of the portion in $€$ ) & $\begin{array}{c}\text { Monetary value assigned to each } \\
\text { attribute }\end{array}$ \\
\hline Functional info & 5.23 & 2.23 \\
Heath info & 5.03 & 2.03 \\
Gluten free info & 1.95 & -1.05 \\
Gluten free from maize & 2.04 & -0.96 \\
10 mins preparation & 1.52 & -1.48 \\
3 mins preparation & 2.39 & -0.61 \\
\hline
\end{tabular}

Results show that in general consumers accepted the proposed innovation. In fact, the case product compared to the alternatives generates aversion as well as the highest level of innovation intensity. On the other hand, the second level presents positive and significant consumers preferences. This result confirms that consumers' trust towards innovation is linked to the level of innovation and that the farthest the worst. Food products, thus, should be proposed on the market with a second type intensity of innovation in order to not generate consumers' mistrust or aversion. In this case, purchasing probability can be maximized as well as market success (Figure 2).

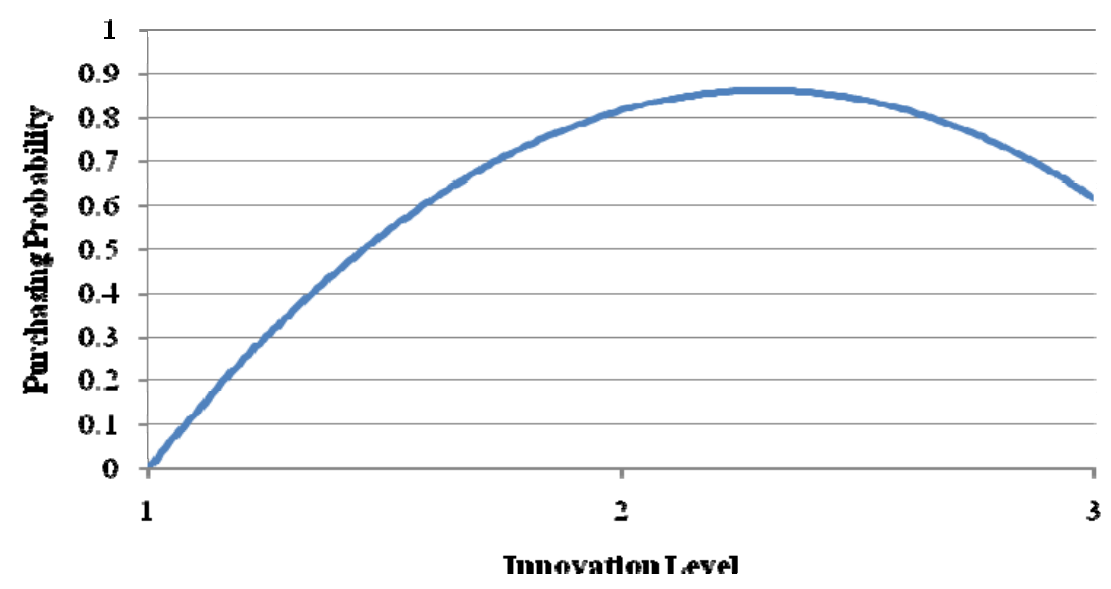

Figure 2. Purchasing probability at different innovation levels 


\section{Conclusion}

To sum up, the study we presented starts as a trial to confirm the need for a cooperative work between food technologists and economists when innovation is going to be patented or produced and released on the market. At this regard, commercial inventions should be supported by a preliminary study conducted by food economists to ascertain the market success instead of the market failure. Optimization and final preparation then should be conducted with a "one at the time" approach (Figure 3). In fact, we showed with this study that quality optimality given the technological possibilities not always corresponds to maximum market success.

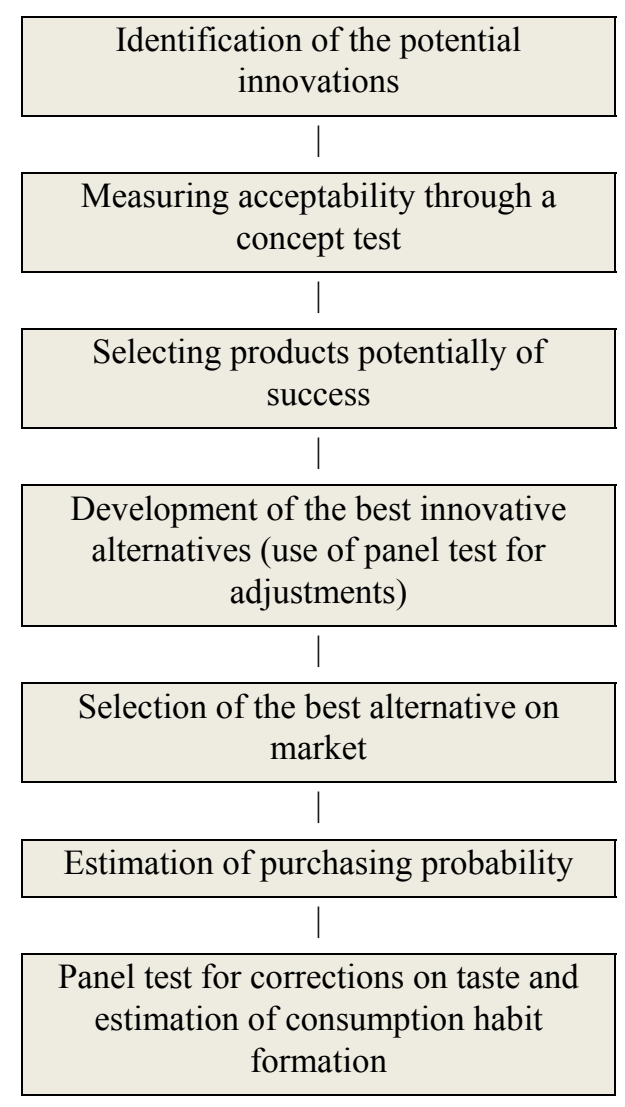

Figure 3. Commercial food innovation development flow

Although the experience has produced more precise results regarding the technological challenge of the team, the experiment is specific and presents just a set of potential innovative quality attributes. Some generic remarks can be drawn: consumers' acceptability of innovative attributes depends on the level of novelty proposed compared to the "not innovative" counterpart; experimental behavior and high education, characteristics of the analyzed segment of population, are assumed to be positively related to novel food purchasing probability, thus, more caution should be used for products that should be proposed to a different type of population; consumers liking the maximum of healthiness and convenience of a food product should not be discounted because aversion and mistrust could not lead to market success.

\section{Acknowledgments}

The research group acknowledges the complete staff of the cafeteria/snack "L'Esperto in Tavola" located in Foggia, which played host to consumers for the interviews on ready to eat meals.

\section{References}

Adamowicz, W., Boxall, P., Williams, M., \& Louviere, J. J. (1998). Stated preference approaches for measuring passive use values: choice experiments and contingent valuation, American Journal of Agricultural Economics, 80, 64-75. http://dx.doi.org/10.2307/3180269

Alzamora, S. M., Salvatori, D., Tapia, S. M., López-Malo, A., Welti-Chanes, J., \& Fito, P. (2005). Novel 
functional foods from vegetable matrices impregnated with biologically active compounds. Journal of Food Engineering, 67, 205-214. http://dx.doi.org/10.1016/j.jfoodeng.2004.05.067

Blamey, R. K., Bennet, J. W., Morrison, M. D., Louviere, J. J., \& Rolfe, J. C. (1998). Attribute selection in environmental choice modeling studies: the effect of casually prior attributes, Choice Modeling Research Report 7, Camberra, A. C. T.: University College, The University of South Wales.

Bennet, J. (1999). Some fundamentals of environmental choice modeling, Choice modeling research report 11. Camberra, A. C. T.: University College, The University of New South Wales.

Bjorner, T. B., Hansen, L. G., \& Russel, C. F. (2004). Environmental labeling and consumers' choice - an empirical analysis of the effect of the Nordic Swan, Journal of Environmental Economics and Management, 47, 411-434. http://dx.doi.org/10.1016/j.jeem.2003.06.002

Brannon, C. A. (2006). Prebiotics as "good carbs". Today's Dietitian, 8, 12-21.

Brennan, C. S., Kuri V., \& Tudorica C. M. (2004). Inulin-enriched pasta: effects on textural properties and starch degradation. Food Chemistry, 86, 189-193. http://dx.doi.org/10.1016/j.foodchem.2003.08.034

Burton, G., Rigby, D., \& Young, T. (2001). Consumers attitude to genetically modified food in the UK. European Review of Agricultural Economics, 28, 479-498. http://dx.doi.org/ 10.1093/erae/28.4.479

Charalampopoulos, D., Pandiella, S. S., \& Webb, C. (2003). Evaluation of the effect of malt, wheat and barley extracts on the viability of potentially probiotic lactic acid bacteria under acidic conditions. International Journal of Food Microbiology, 82, 133-141. http://dx.doi.org/10.1016/S0168-1605(02)00248-9

Charalampopoulos, D., Wang, R., Pandiella, S., \& Webb, C. (2002). Application of cereals and cereal components in functional foods: A review. International Journal of Food Microbiology, 79, 131-141. http://dx.doi.org/10.1016/S0168-1605(02)00187-3

Chillo, S., Laverse, J., Falcone, P. M., \& Del Nobile, M. A. (2007). Effect of carboxymethylcellulose and pregelatinized corn starch on the quality of amaranthus spaghetti, Journal of Food Engineering, 83, 492-500. http://dx.doi.org/10.1016/j.jfoodeng.2007.03.037

Cicia, G., Del Giudice, T., \& Esposito, P. (2004). Semplicità operativa VS completezza nell'analisi delle preferenze del consumatore: un confronto tra conjoint analysis e modelli a utilità stocastica, in Antonelli G. (a cura di): Marketing agro-alimentare, specificità e temi di analisi, Milano, Franco Angeli.

Cicia, G., Del Giudice, T., \& Scarpa, R. (2002). Consumers' Perception of Quality in Organic Food: a Random Utility Model under Preference Heterogeneity and Choice Correlation from Rank-orderings, British Food Journal, 104, (3,4,5). http://dx.doi.org/ 10.1108/00070700210425660

Collar, C., Santos, E., \& Rosell, C. M. (2006). Significance of dietary fiber on the viscometric pattern of pasted and gelled flour-fiber blends, Cereal Chemistry, 83, 370-376. http://dx.doi.org/10.1094/CC-83-0370

Dello Staffolo, M., Bertola, N., Martino, M., \& Bevilacqua, A. (2004). Influence of dietary fiber addition on sensory and rheological properties of yogurt. International Dairy Journal, 14, 263-268. http://dx.doi.org/10.1016/j.idairyj.2003.08.004

Gibson, G. R. (2004). From probiotics to prebiotics and a healthy digestive system. Journal of Food Science, 69 , 141-143. http://dx.doi.org/10.1111/j.1365-2621.2004.tb10724

Gilbert, L. (1997). The consumer market for functional food. Journal of Nutraceuticals, Functional and Medical Foods, 1, 5-21.

Glanz, K., Basil, M., Maibach, E., Goldberg, J., \& Snyder, D. (1998). Why Americans eat what they do: taste, nutrition, cost, convenience, and weight control concerns as influences on food consumption. Journal of the American Dietetic Association, 98, 1118-1126. http://dx.doi.org/10.1016/S0002-8223(98)00260-0

Grunert, K. G., Bech-Larsen, T., \& Bredahl, L. (2000). Three issues in consumer quality perception and acceptance of dairy products. International Diary Journal, 10, 575-584. http://dx.doi.org/10.1016/S0958-6946(00)00085-6

Hansen, L., \& Sshmidt, M. (1999). Revisiting Conjoint: how Danish pig producers found the future road to environmentally concerned Danish consumers (mimeo).

Iwe, M. O. (2002). Handbook of Sensory Methods and Analysis. Rojoint Communication Services Ltd., Enugu, Nigeria.

Jones, P. J., \& Jew, S. (2007). Functional food development: Concept to reality. Trends in Food Science \& 
Technology, 18, 387-390. http://dx.doi.org/10.1016/j.tifs.2007.03.008

Kociubinski, G., \& Salminen, S. (2006). Probiotics: Basis, state of the art and future perspectives. Functional food network general meeting.

McFadden, D. (1974). Conditional logit analysis of qualitative choice behaviour. In: Zarembka, P. (Ed), Frontiers in Econometrics, Academic press, New York, 105-142.

Meilgaard, M., Civille, G. V., \& Carr, B. T. (1999). Sensory Evaluation Techniques. 3rd Ed. USA: CRC Press LLC.

Morrison, M. D., Blamey, R. K., Bennet, J. W., \& Louviere, J. J. (1996). A comparison of stated preferences techniques for estimating environmental values, Choice Modeling Research Reports, Camberra, A. C. T. The University of New South Wales.

Nayga, R. M., Jr. (1996). Determinants of consumers' use of nutritional information on food packages. Journal of Agricultural and Applied Economics, 28, 303-312.

Niva, M. (2007). 'All foods affect health': Understandings of functional foods and healthy eating among health-oriented Finns. Appetite, 48, 384-393. http://dx.doi.org/ 10.1016/j.appet.2006.10.006

Petitot, M., Boyer, L., Minier, Ch., \& Micard, V. (2010). Fortification of pasta with split pea and faba bean flours: Pasta processing and quality evaluation. Food Research International, 43, 634-641. http://dx.doi.org/10.1016/j.foodres.2009.07.020

Reilly, M. D. (1982). Working wives and convenience consumption. Journal of Consumer Research, 8, 407-418. http://dx.doi.org/10.1086/208881

Roselli, L., Seccia, A., \& Stasi, A. (2006). Atteggiamento dei consumatori nei confronti dell'evoluzione del sistema agro-alimentare: l'introduzione di alimenti geneticamente modificati, Rivista di Economia Agro-alimentare, 1, 127-150.

Saarela, M., Lähteenmäki, L., Crittenden, R., Salminen, S., \& Mattila-Sandholm, T. (2002). Gut bacteria and health foods-The European perspective. International Journal of Food Microbiology, 78, 99-117. http://dx.doi.org/10.1016/S0168-1605(02)00235-0

Shah, N. P. (2007). Functional cultures and health benefits. International Dairy Journal, 17, 1262-1277. http://dx.doi.org/10.1016/j.idairyj.2007.01.014

Singh, N., Singh, J., Kaur, K., Sodhi, N. S., \& Gill, B. S. (2003). Morphological, thermal and rheological properties of starches from different botanical sources. Food Chemistry, 81, 219-231. http://dx.doi.org/10.1016/S0308-8146(02)00416-8

Sloan, A. E. (2000). The top ten functional food trends. Food Technology, 54, 33-62.

Sloan, A. E. (2002). The top 10 functional food trends. The next generation. Food Technology, 56, 32-57.

Sloan, A. E. (2004). The top ten functional food trends. Food Technology, 58, 28-51.

Stanton, C., Ross, R. P., Fitzgerald, G. F., \& Van Sinderen, D. (2005). Fermented functional foods based on probiotics and their biogenic metabolites. Current Opinion in Biotechnology, 16, 198-203. http://dx.doi.org/10.1016/j.copbio.2005.02.008

Stasi, A., Carlucci, D., \& Seccia, A. (2008). Informazione Asimmetrica e Regolamentazione per l'Etichettatura del Vino, Rivista di Economia Agraria, 2.

Tolstoguzov, V. (2003). Thermodynamic considerations of starch functionality in foods, Carbohydrate Polymers, 51, 99-111.

Train, K. (2009). Discrete choice method with simulation (2nd ed.). Cambridge University Press.

Verlegh, P. W. J., \& Candel, M. J. J. M. (1999). The consumption of convenience foods: reference groups and eating situations. Food Quality and Preference, 10, 457-464. http://dx.doi.org/10.1016/S0950-3293(99)00042-7

Weststrate, J. A., Van Poppel, G., \& Verschuren, P. M. (2002). Functional foods, trends and future. British Journal of Nutrition, 88, 233-235. http://dx.doi.org/10.1079/BJN2002688 